\title{
MSI test to distinguish between HNPCC and other predisposing syndromes - of value in tailored surveillance ${ }^{1}$
}

\author{
Annelie Liljegren ${ }^{\mathrm{a}, \mathrm{c}}$, Louise Olsson ${ }^{\mathrm{b}}$ and Annika Lindblom ${ }^{\mathrm{a}, *}$ \\ ${ }^{a}$ Department of Molecular Medicine, Karolinska Institutet, S171 76 Stockholm \\ ${ }^{\mathrm{b}}$ Department of Surgery, Eskilstuna Hospital, Sweden \\ ${ }^{\mathrm{c}}$ Department of Oncology and Pathology, Karolinska Institutet, S-17176 Stockholm, Sweden
}

\section{Introduction}

Colorectal cancer can serve as an excellent model for cancer prevention. Tumors start as early premalignant lesions, easy to detect and remove, progress over adenoma with a varying degree of atypia into carcinomas [1]. Thus, early detection is possible and of major importance in reducing the morbidity and mortality in colorectal cancer.

During the last decade much new knowledge has come to light concerning the hereditary forms of colorectal cancer. The number of individuals participating in prevention programs is increasing and includes healthy high-risk individuals [2,3]. These prevention programs comprise genetic counseling and when possible, predictive genetic testing. Regular colonoscopies provided for high-risk individuals have resulted in decreased incidence of and mortality from colorectal cancer [4]. This surveillance is well tolerated and understood by those included in these preventive programs [5].

\footnotetext{
${ }^{1}$ This work was supported by the Swedish Cancer Society, The Stockholm Cancer Society, the Nilson-Ehle Foundation, the Swedish EU-R\&D Foundation and the Swedish Society of Medicine.

* To whom requests for reprints should be addressed: A. Lindblom, at Department of Molecular Medicine, CMM L8:02, Karolinska Institutet, S-171 76 Stockholm, Sweden. Tel.: +46 85177 5248; Fax: +46 85177 3620; E-mail: annika.lindblom@cmm.ki.se.
}

\subsection{A family history of colorectal cancer is associated with an empirically increased risk of the disease}

Numerous studies have been performed in an effort to delineate the excess risk of colorectal cancer in family members. First-degree relatives of persons with colorectal cancer have been found to have a RR of around 3 of a large bowel malignancy compared to a control group [6-8]. The risk is also depending of age of onset of diagnosis in the relatives.

\subsection{Familial colorectal cancer}

Inherited colorectal cancer syndromes could be delineated based on the pathology of the polyp such as adenoma including Familial adenomatous polyposis (FAP) [9] and Hereditary non-polyposis syndrome (HNPCC) [10], or hamartoma comprising PeutzJeghers syndrome, Juvenile polyposis and Cowden syndrome. A milder phenotype of FAP, called attenuated FAP has been described, and is caused by mutations at the extreme 5' or 3' ends of the APC gene [11]. MuirTorre's syndrome is considered to be a subtype of HNPCC [12]. In Turcot's syndrome, germline mutations in the APC gene as well as the mismatch repair genes have been reported $[13,14]$. 


\section{Hereditary nonpolyposis colorectal cancer (HNPCC)}

In any population, the frequency of HNPCC (or any other syndrome) varies with the criteria used to define the syndrome. Selection bias in the group investigated or the use of different study protocols would also influence an estimation of the frequency. Another reason for diverging results could be a genuine geographic or ethnic variation. The overall incidence of colorectal cancer is also of importance as the familial frequency is boosted in low-incidence areas. One obvious difficulty with epidemiological studies on HNPCC is the lack of a specific phenotype, distinguishing it from sporadic colorectal cancer. In 1990, it was therefore decided upon minimum criteria of HNPCC (Amsterdam I) [15]. This first operational definition of the syndrome was formulated mainly for research purposes and as such they focused on specificity rather than sensitivity. With time it was perceived they were too strict for clinical practice and not enough helpful in identifying families for genetic counseling and surveillance. A looser set of criteria were formulated (Amsterdam II) [16] including associated malignancies such as endometrial, small bowel, ureter and renal pelvis cancer. No minimum numbers of relatives affected or age specifications were demanded. A few population-based studies on the frequency of HNPCC using clinical criteria have been published and are summarized in Table 1 [17-23]. The identification of germline mismatch repair deficiency as the molecular basis of HNPCC [24-26] has made possible another way of estimating the frequency of the syndrome. A higher percentage of MLH1 and MSH2 mutations have been found in families complying fully with the Amsterdam I criteria [27]. The frequency of HNPCC varies in different populations. One example is the Finnish population where a widespread ancestral founder mutation on the MLH1 gene explains the high frequency of HNPCC. In most Western countries, it seems reasonable to estimate the frequency to about $1 \%$. Studies estimating the frequency with a molecular approach are summarized in Table 2 [28-32]. Still, these figures could be underestimated since most mutation screening studies report mutations only in about $50 \%$ of HNPCC cases [27,33-35].

\section{Unknown colorectal cancer syndromes}

These syndromes can be classified in high risk or low risk families depending on the number of afflicted members in the family. The studies related above on HNPCC clearly demonstrates the difficulties to estimate the frequency of a syndrom with a complex phenotype. We conducted a study aiming to determine the frequency of the unknown remaining colorectal cancer syndromes. The high-risk families and low risk families were estimated to 1.9 and $8.3 \%$ respectively in a Swedish county, shown in Fig. 1 [23]. Families with a family history of three or more first-degree relatives with colorectal cancer are likely to segregate predisposing mutations in high-risk genes, causing hereditary colorectal cancer [2,3]. Families without mutations in the DNA mismatch repair genes are likely to segregate germline mutations in yet unknown predisposing genes. In fact, a locus for non-HNPCC familial colorectal cancer was recently published [36].

Low risk families can be described as two close relatives with colorectal cancer. This occurrence may result from a combination of inherited susceptibility and shared environmental factors. Kindred studies have found that common familial risk probably arises from mildly to moderately penetrant inherited susceptibility factors [37-39]. These studies indicate that the predisposition for colorectal cancer is common in the population and may account for a substantial fraction of colon cancer cases. The presence of low penetrant genes may be an explanation for the development of colorectal cancer in the low risk families. These types of genes can comprise subtle sequence variants or polymorphisms and may be associated with a small-moderate increased risk for colorectal cancer [38,39].

\section{Phenotype in HNPCC and the unknown syndromes}

Typically, an early age of onset of colorectal cancer is similar in FAP and HNPCC. However, adenoma are seen decades earlier in FAP compared to HNPCC. Another striking difference between these two syndromes is the number of adenoma and the cancer risk in each adenoma [40]. We hypothesize that tumors not associated with DNA mismatch repair deficiency arose from different carcinogenic pathways and thus showed some phenotypic similarities and differences, as do FAP and HNPCC.

\subsection{Prevalence of adenomas}

The prevalence of sporadic colorectal adenomatous polyps increases with age [41]. Autopsy studies 
Table 1

\begin{tabular}{lclcc}
\hline Location & Year & Criteria & HNPCC frequency & Comment \\
\hline Denmark [Katballe, 2002 \#17] & $95-98$ & Amsterdam I and II & 1.5 (95 \% CI 0.8-2.2) \\
UK [Evans, 1997 \#18] & $81-95$ & Amsterdam I 0.3 Amsterdam II 1.4 & 0.9 (95\% CI 0.3-2.1) \\
USA [Peel, 2000 \#19] & $94-96$ & Amsterdam I & 3.4 & Low-incidence area \\
Italy [Ponz de Leon, 1993 \#20] & $84-89$ & Amsterdam I & 3.8 & 0.7 \\
Finland [Mecklin, 1987 \#21] & $70-79$ & At least three first-degree relatives & with CRC & $1.2(95 \%$ CI 0.2-2.2) \\
& & Amsterdam I & \\
Finland [Mecklin, 1995 \#22] & & Amsterdam I & \\
Sweden [Olsson L, 2003 \#23] & $98-01$ & &
\end{tabular}

Table 2

Germ-line mutated MLH1 and MSH2 and the frequency of HNPCC

\begin{tabular}{lccl}
\hline Location & Year & HNPCC frequency & Comment \\
\hline Finland [Aaltonen, 1998 \#28]. & $94-96$ & $2 \%$ & $5 / 10$ founder mutations \\
Finland [Salovaara, 2000 \#29] & $96-98$ & $3.4 \%$ & $13 / 18$ founder mutations \\
Slovenia [Ravnik-Glavac, 2000 \#30]. & $96-98$ & $1.3 \%$ & \\
USA [Samowitz, 2001 \#31]. & $91-94$ & 0.86 & Colon cancer only \\
Italy [Percesepe, 2001 \#32] & $96-97$ & $0.3(95 \%$ CI 0-0.9) & High-incidence area \\
\hline
\end{tabular}

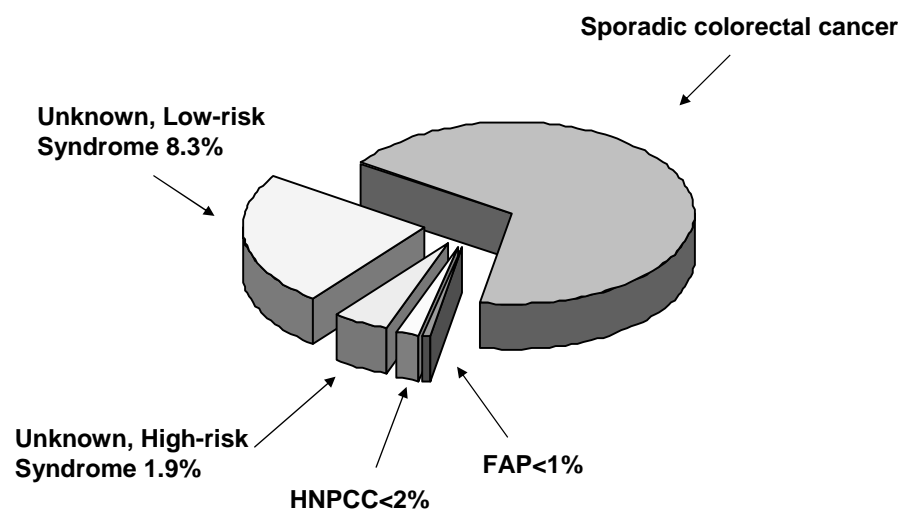

Fig. 1. Circle diagram demostrating the frequencies of different colorectal cancer cases with respect to genetic background (from Olsson L. and Lindblom A.: Family history of colorectal cancer in a Sweden county, Fam Cancer 2 (2003), 87-93).

show that the prevalence of adenoma is between $22 \%-$ $36 \%[42,43]$. Prevalence of adenoma in individuals with hereditary colorectal cancer is reported in several studies. There is a wide variation from $14 \%-25 \%$ [3, 44]. In our experience, HNPCC cases as well as cases in the remaining syndromes show more adenoma than a control population [2]. When we compared the prevalence of adenoma in subjects from HNPCC and unknown syndromes, there was a tendency for both high risk and low risk family members to have more adenoma $[2,3]$.

\subsection{Prevalence of hyperplastic polyps}

Hyperplastic polyps have been found frequently in patients with colorectal carcinoma [45]. Prevalence numbers in the general population vary in different studies. In individuals over the age of 50 years the prevalence of hyperplastic polyps has been determined to be $20-40 \%[41,43]$. Few reports present the prevalence of hyperplastic polyps in HNPCC. In one study from 1998, the prevalence of hyperplastic polyps was $14 \%$ in HNPCC and $8 \%$ in a matched control group without a family history of colorectal cancer [46]. In our Swedish cohort of risk subjects, including HNPCC and individuals from other high risk and low risk families, the prevalence of hyperplastic polyps was $9.3 \%$, $15.7 \%$, and $31.3 \%$ respectively in this risk groups [3].

\subsection{An association between adenoma and hyperplastic polyps}

An association of hyperplastic polyps with synchronous findings of adenoma has been reported in several autopsy studies $[41,47]$. The presence of synchronous adenoma and hyperplastic polyps indicate 


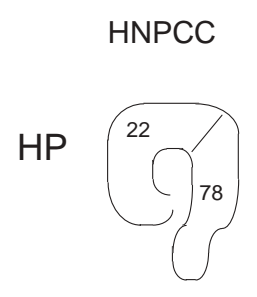

A

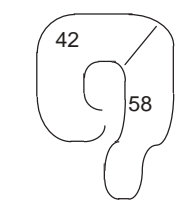

$\mathrm{C}$

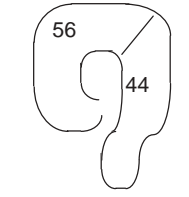

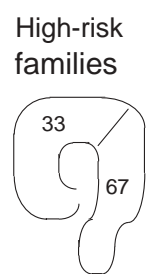
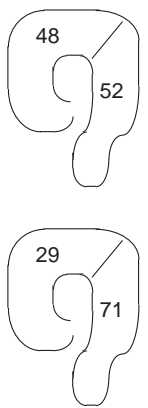

Low-risk

families
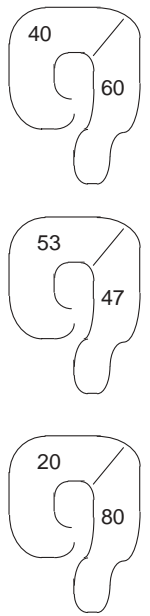

Fig. 2. Frequency (\%) of carcinomas (C), adenomas (A) and hyperplastic polyps (HP) in different colorectal cancer cases with respect to genetic background (Liljegren A. et al., Prevalence and incidence of hyperplastic polyps and adenomas in familial colorectal cancer: correlation between the two types of colon polyps, Gut 52 (2003), 1140-7).

that some of the hyperplastic polyps have a malignant potential or are both polyps attributed to the same underlying genetic factor. A significant association of adenoma and hyperplastic polyps was found in screening individuals having one or two close relatives with colorectal cancer [48]. In the analyses of our Swedish cohort including HNPCC and individuals from high risk and low risk families, a significant association between hyperplastic polyps and adenoma was found in HNPCC as well as both high risk and low risk unknown syndromes [3]. Thus, hyperplastic polyps could potentially be used to identify high-risk individuals in all syndromes with increased risk of colorectal cancer [3].

\subsection{Age of onset of adenoma and carcinomas}

The mean age of onset of adenoma and carcinomas in HNPCC and the unknown syndromes were studied, and we found that the age of onset for the unknown syndromes was around 10 years older compared to HNPCC $[2,3]$. In the study of prevalence of various syndromes in a Swedish county, only HNPCC patients were younger at onset compared to sporadic cases [23]. However, the difference was less clear in this population based study than previously reported.

\subsection{Location of tumors in the colon}

Several authors suggest a proximal and a distal pathway to colorectal cancer $[40,49,50]$. In a meta analysis,
8 of 11 studies distinguished between colon and rectal cancer index cases, the cancer risk in relatives was greater if the index case had colon cancer rather than rectal cancer [51]. A model combining the data of tumors displaying high microsatellite instability (MSIH) and microsatellite stable (MSS) tumors with data on environmental exposure has also been suggested [52]. Additional support for different pathways to colorectal cancer is the different distribution of MSIH and MSS tumors in the colon. Almost all sporadic MSIH cancers occur in the proximal colon, whereas most sporadic MSS cancers are distributed more distal $[53,54]$. Similarly, MSS cancers in FAP are often distal while MSIH cancers in HNPCC are more proximal [40].

The colorectal distribution of carcinomas, adenoma and hyperplastic polyps in HNPCC and in high- and low risk familial colorectal cancer syndromes is shown in Fig. 2 [3].

Sporadic adenoma are evenly distributed in the colon although there is a shift from distal to proximal location in older age groups [55]. The published proximal distribution of adenoma in HNPCC varies from $28 \%$ to $82 \%$ [3,56,57]. In our studies, adenoma in HNPCC as well as the unknown syndromes were quite evenly distributed (Fig. 2) [2,3]. However, the distribution of carcinomas differed among those groups. In HNPCC, the carcinomas were slightly more proximal than adenoma, suggesting a higher risk of cancer in proximal adenoma in this syndrome (Fig. 2). In contrast, in the unknown syndromes the distribution of carcinomas was clearly 
more distally oriented compared to adenoma, suggesting a higher risk of cancer in distal adenoma (Fig. 2) [3, 40]. Hyperplastic polyps in HNPCC are reported to be predominantly located in the distal colon $(>70 \%)[3$, 58]. Hyperplastic polyps in the MSS high- and low risk syndromes were also distributed distal, although not to the same degree as in HNPCC (Fig. 2) [3].

\subsection{The cancer risk in adenoma}

Most polyps grow to a certain size and then go into spontaneous regression [59]. Five to 10 percent of all adenoma will develop carcinoma [60]. The cancer risk in adenoma seems to vary depending on genetic background. In a recent study, that involved a three-year follow up, adenoma in individuals with a family history of colorectal cancer increased significantly more in size than those in a control group without family history of colorectal cancer [61]. This indicated a higher cancer risk in the adenoma in subjects with a family history of colorectal cancer [61]. Moreover, there is an obvious difference in cancer risk in an adenoma in FAP, where there are up to thousands of adenoma of which one becomes malignant after decades, compared to a single adenoma in HNPCC with a high risk of malignification within a year [40]. From our studies, it seems that also the cancer risk in adenoma in subjects from the other MSS high- and low risk syndromes varies between syndromes. The cancer risk in adenoma in all MSS syndromes seems lower than that in HNPCC [2]. Moreover, since the low risk subjects tended to have more adenoma in relation to their lower expected cancer risk, the cancer risk in adenoma from low risk family members seemed lower than that in high risk members [2]. We conclude that the lower observed risk of cancer in the low risk families do not depend on few adenoma, but rather on a much lower risk of cancer in the adenoma [2]. The difference in distribution of adenoma and carcinomas in the various syndromes discussed above also suggest that the cancer risk might differ in depending on location in each syndrome.

\subsection{The cancer risk in hyperplastic polyps}

There is considerable evidence that adenoma in one individual are associated with a significant increased risk for future adenoma in the same person $[62,63]$. Hyperplastic polyps may also act as predictors for subsequent development of adenoma or carcinomas. In one study, patients with hyperplastic polyps were 2.4 times more likely to have further adenoma than those without polyps [64]. Although some studies have suggested a pathway where hyperplastic polyps develop over serrated adenoma into carcinomas [65], most hyperplastic polyps are not likely to confer a cancer risk of their own.

\section{MSI test to distinguish between HNPCC and unknown syndromes}

MSI (or immunohistochemistry) is today commonly used in a clinical setting to define patients with germline mutations in the DNA mismatch repair genes [27,6668]. The MSI test then automatically also define the patients likely to have mutations in the remaining unknown predisposing genes, provided the MSI test is applied to a patient with a family history or early onset of colorectal cancer. Even if MSIH is a hallmark of HNPCC, it cannot be used to define HNPCC in unselected cases since, although $15 \%$ of those are MSIH, the vast majority of those unselected cases are sporadic [68,69]. The sensitivity is improved if the MSI test is limited to pre-selected cases [27,66-68].

\subsection{MSIH defines HNPCC in a familial case}

How reliable is MSIH in a familial case to predict HNPCC with germline mutations in DNA mismatch repair genes? In colorectal cancer families with MSIH tumors, germline mutations are detected in a high proportion [70-73]. Yet, there are cases where no mutation is found [70-73]. This could be explained by the techniques used for mutation detection $[70,71]$. However, even if using several methods detecting missense and nonsense mutations, deletions or insertions of a few nucleotides as well as deletions and duplications of whole exons, still there are unexplained cases with MSIH tumors [71-75]. A MSIH tumor could represent a false positive case if the MSI test to define HNPCC used only one tumor in a family. This tumor could be from a sporadic MSIH case or a familial non-HNPCC case where the MSIH phenotype is somatically derived. Somatic mutations in the MMR genes are rare but can sometimes explain a single MSIH case [76,77]. However, familial non-HNPCC cases as well as HNPCC cases can show MSIH associated with a somatic methylation [78-82]. Yet, it can not be ruled out that other predisposing genes causing MSIH tumors exist. MSIH tumors with expression of all MMR proteins have been described [83-85]. Unknown genes causing MSIH tumors could cause these cases, but often a repeated MSI and/or immunohistochemistry analysis on a new portion of the tumor would clearify this issue. 
Table 3

\begin{tabular}{lllc}
\hline \multicolumn{4}{c}{ Colorectal screening recommendations in Sweden } \\
\hline Syndrome & Screening tool & Age to start & Interval, y \\
\hline HNPCC & $\begin{array}{l}\text { Colonoscopy } \\
\text { High risk CRC }\end{array}$ & $\begin{array}{l}\text { Colonoscopy } \\
10 \text { y younger than the earliest diagnosis in }\end{array}$ & $\begin{array}{l}10 \text { y } \\
\text { the family }\end{array}$ \\
Low risk CRC & Colonoscopy & $\begin{array}{l}10 \text { y younger than the earliest diagnosis in } \\
\text { the family }\end{array}$ & $3-5$ \\
\hline
\end{tabular}

(with permission from the Swedish Oncogenetic Study group).

\subsection{MSS defines non-HNPCC syndromes in a familial case}

How reliable is MSS in a familial case to predict a non-HNPCC case with a germline mutation in other predisposing genes? Could a MSS tumor come from a patient with a germline mutation in a DNA mismatch repair gene? Families with missense mutations in MLH1 or MSH2 with MSS tumors have been described [86, 87]. However, those families are rare and when they are seen it is difficult to offer genetic testing since it is not clear whether the mutation is pathogenic or not [86, 87]. Moreover, a MSS case could also constitute a false negative if the wrong person was chosen for MSI test. Even in HNPCC families sporadic MSS cases occur and there are even examples of families where several predisposing mutations exist in the same family, one in a DNA mismatch repair gene associated with MSIH tumors and another segregating with MSS tumors (unpublished data).

Still, if careful selection of the case for MSI test (or immunohistochemistry) is used in a family in counseling, one tumor should be sufficient to give the correct answer in most families to distinguish between HNPCC and another syndromes with MSS tumors.

\section{Surveillance to all risk subjects - tailored after syndrome}

When a genetic investigation fails to define the a germline predisposing mutation in a family, risk estimates for the family members should be based on empiric risk figures. All risk individuals should be offered tailored surveillance program. In FAP, usually surveillance is undertaken until onset of polyps when prophylactic surgery is recommended. In all other colorectal cancer syndromes various surveillance programs are recommended. To optimize the preventive strategy one should use the knowledge on each syndrome regarding the type and number of polyps, as well as the location of and the actual cancer risk in the polyps. Recently, recommendations have been outlined in Sweden regarding the surveillance in families with increased risk of colorectal cancer (Table 3). Various reports have provided guidelines for recommendations in different syndromes and risk settings [88-92]. It should be emphasized that the guidelines are empiric and rational, but not based on prospective controlled studies. A $10 \%$ or greater lifetime risk of dying from colorectal cancer has been suggested to represent an appropriate level of screening [93].

In conclusion, by taking a family history in all patients with a diagnosed colorectal cancer there is a chance to detect an increased risk of the disease in close relatives. Those families should be offered genetic counseling and surveillance. In the counseling procedure a simple MSI test will define HNPCC with a possible detection of a germline mutation in the mismatch repair genes and pre-symptomatic testing and preventive programs suitable for this syndrome. The MSI test will at the same time define non-HNPCC high-risk or low risk families segregating as yet unknown predisposing genes. The known phenotypic differences allow specific surveillance also in these families, while mutation testing will have to wait until the unknown genes are defined. By offering all risk subjects surveillance it is possible to prevent colorectal cancer in the whole cohort of thus defined predisposed individuals.

\section{References}

[1] E.R. Fearon and B. Vogelstein, A genetic model for colorectal tumorigenesis, Cell 61 (1990), 759-767.

[2] G. Lindgren, A. Liljegren and E. Jaramillo, Adenoma prevalence and cancer risk in familial non-polyposis colorectal cancer, Gut 50 (2002), 228-234.

[3] A. Liljegren, A. Lindblom and S. Rotstein, Prevalence and incidence of hyperplastic polyps and adenomas in familial colorectal cancer: correlation between the two types of colon polyps, Gut 52 (2003), 1140-1147.

[4] H.J. Järvinen, M. Aarnio and H. Mustonen, Controlled 15year trial on screening for colorectal cancer in families with hereditary nonpolyposis colorectal cancer, Gastroenterology 118 (2000), 829-834. 
[5] A. Liljegren, G. Lindgren and Y. Brandberg, Individuals with an increased risk for colorectal cancer - perceived benefit and psychological aspects on surveillance by means of regular colonoscopies, Int J Clin Oncol, under revision.

[6] C.M. Woolf, A genetic study of carcinoma of the large intestine, Am J Hum Genet 10 (1958), 42-47.

[7] M.T. Macklin, Inheritance of cancer of the stomach and large intestine in man, J. Natl Cancer Inst 24 (1960), 551-571.

[8] E. Lovett, Family studies in cancer of the colon and rectum, Br J Surg 63 (1976), 13-18.

[9] R.W. Burt and J. Groden, The genetic and molecular diagnosis of adenomatous polyposis coli, Gastroenterology 104 (1993), 1211-1214.

[10] H. Lynch and A. de la Chapelle, Genetic susceptibility to nonpolyposis colorectal cancer, J Med Genet 36 (2000), 801-818.

[11] L. Spirio, S. Olschwang and J. Groden, Alleles of the APC gene: an attenuated form of familial polyposis, Cell 75 (1993), 951-957.

[12] M. Mathiak, A. Rutten and E. Mangold, Loss of DNA mismatch repair proteins in skin tumors from patients with MuirTorre syndrome and MSH2 or MLH1 germline mutations: establishment of immunohistochemical analysis as a screening test, Am J Surg Pathol 26 (2002), 338-343.

[13] C.M. Tops, H.F. Vasen and G. van Berge Henegouwen, et al., Genetic evidence that Turcot syndrome is not allelic to familial adenomatous polyposis, Am J Med Genet 43 (1992), 888-893.

[14] S.R. Hamilton, B. Liu and R.E. Parsons, et al., The molecular basis of Turcot's syndrome, N Engl J Med 332 (1995), 839847.

[15] H.F. Vasen, J.P. Mecklin and P.M. Khan, et al., The International Collaborative Group on Hereditary Non-Polyposis Colorectal Cancer (ICG-HNPCC), Dis Colon Rectum 34 (1991), 424-425.

[16] H.F. Vasen, P. Watson and J.P. Mecklin, et al., New clinical criteria for hereditary nonpolyposis colorectal cancer (HNPCC, Lynch syndrome) proposed by the International Collaborative group on HNPCC, Gastroenterology 116 (1999), 1453-1456.

[17] N. Katballe, M. Christensen and F.P. Wikman, et al., Frequency of hereditary non-polyposis colorectal cancer in Danish colorectal cancer patients, Gut 50 (2002), 43-51.

[18] D.G. Evans, S. Walsh and J. Jeacock, et al., Incidence of hereditary non-polyposis colorectal cancer in a populationbased study of 1137 consecutive cases of colorectal cancer, $\mathrm{Br}$ J Surg 84 (1997), 1281-1285.

[19] D.J. Peel, A. Ziogas and E.A. Fox, et al., Characterization of hereditary nonpolyposis colorectal cancer families from a population-based series of cases, J Natl Cancer Inst 92 (2000), 1517-1522.

[20] M. Ponz de Leon, R.S. Piero Benatti and L. Roncucci, Identification of Hereditary Nonpolyposis Colorectal Cancer in the General Population, Cancer 71 (1993), 3493-3501.

[21] J.P. Mecklin, Frequency of hereditary colorectal carcinoma, Gastroenterology 93 (1987), 1021-1025.

[22] J.P. Mecklin, H.J. Jarvinen and A. Hakkiluoto, et al., Frequency of hereditary nonpolyposis colorectal cancer, A prospective multicenter study in Finland, Dis Colon Rectum 38 (1995), 588-593.

[23] L. Olsson and A. Lindblom, Family history of colorectal cancer in a Sweden county, Fam Cancer 2 (2003), 87-93.

[24] F.S. Leach, N.C. Nicolaides and N. Papadopoulos, et al., Mutations of a mutS homolog in hereditary non-polyposis colorectal cancer, Cell 17 (1993), 1215-1225.

[25] C.E. Bronner, S.M. Baker and P.T. Morrison, et al., Mutation in the DNA mismatch repair gene homologue hMLH1 is as- sociated with hereditary non-polyposis colon cancer, Nature 17 (1994), 258-261.

[26] N. Papadopoulos, N.C. Nicolaides and Y.F. Wei, et al., Mutation of a mutL homolog in hereditary colon cancer, Science 18 (1994), 1625-1629.

[27] T. Liu, S. Wahlberg and E. Burek, et al., Microsatellite instability as a predictor of a mutation in a DNA mismatch repair gene in familial colorectal cancer, Genes Chromosomes Cancer 27 (2000), 17-25.

[28] L.A. Aaltonen, R. Salovaara and P. Kristo, et al., Incidence of hereditary nonpolyposis colorectal cancer and the feasibility of molecular screening for the disease, $N$ Engl $J$ Med 338 (1998), 1481-1487.

[29] R. Salovaara, A. Loukola and P. Kristo, et al., Populationbased molecular detection of hereditary nonpolyposis colorectal cancer, J Clin Oncol 18 (2000), 2193-2200.

[30] M. Ravnik-Glavac, U. Potocnik and D. Glavac, Incidence of germline hMLH1 and hMSH2 mutations (HNPCC patients) among newly diagnosed colorectal cancers in a Slovenian population, J Med Genet 37 (2000), 533-536.

[31] W.S. Samowitz, K. Curtin and H. Lin, et al,. The colon cancer burden of genetically defined hereditary nonpolyposis colon cancer, Gastroenterology 121 (2001), 830-838.

[32] A. Percesepe, F. Borghi and M. Menigatti, et al., Molecular screening for hereditary nonpolyposis colorectal cancer: a prospective, population-based study, J Clin Oncol 19 (2001), 3944-3950.

[33] M. Planck, A. Koul and E. Fernebro, et al., hMLH1, hMSH2 and hMSH6 mutations in hereditary non-polyposis colorectal cancer families from southern Sweden, Int J Cancer $\mathbf{8}$ (1999), 197-202.

[34] J.T. Wijnen, H.F. Vasen and P.M. Khan, et al., Clinical findings with implications for genetic testing in families with clustering of colorectal cancer, N Engl J Med 339 (1998), 511-518.

[35] Q. Wang, C. Lasset and F. Desseigne, et al., Prevalence of germline mutations of hMLH1, hMSH2, hPMS1, hPMS2, and hMSH6 genes in 75 French kindreds with nonpolyposis colorectal cancer, Hum Genet 105 (1999), 79-85.

[36] G.L. Wiesner, D. Daley and S. Lewis, et al., A subset of familial colorectal neoplasia kindreds linked to chromosome 9q22.2-31.2, Proc Natl Acad Sci USA 100 (2003), 1296112965.

[37] L.A. Cannon-Albright, M.H. Skolnick and D.T. Bishop, et al., Common inheritance of susceptibility to colonic adenomatous polyps and associated colorectal cancers, $N$ Engl J Med 319 (1988), 533-537.

[38] R.S. Houlston and I.P.M. Tomlinson, Polymorphisms and colorectal tumor risk, Gastroenterology 121 (2001), 282-301.

[39] M.M. de Jong, H.M. Nolte and G.J. te Meerman, et al., Cancer Epidemiol, Biomarkers, Prevention 11 (2002), 1332-1352.

[40] A. Lindblom, Different mechanisms in the tumorigenesis of proximal and distal colon cancers, Curr Opin Oncol 13 (2001), 63-69.

[41] A.R. Williams, B.A. Balasooriya and D.W. Day, Polyps and cancer of the large bowel: a necropsy study in Liverpool, Gut 23 (1982), 835-842.

[42] L.G. Johannsen, O. Momsen and N.O. Jacobsen, Polyps of the large intestine in Aarhus, Denmark, An autopsy study. Scand J, Gastroenterol 24 (1989), 799-806.

[43] M.H. Vatn and H. Stalsberg, The prevalence of polyps of the large intestine in Oslo: an autopsy study, Cancer 49 (1982), 819-825.

[44] J.G. Guillem, K.A. Forde and M.R. Treat, et al., Colonoscopic screening for neoplasms in asymptomatic first-degree relatives 
of colon cancer patients, A controlled, prospective study, Dis Colon Rectum 35 (1992), 523-529.

[45] T.J. Eide, Prevalence and morphological features of adenomas of the large intestine in individuals with and without colorectal carcinoma, Histopathology 10 (1986), 111-118.

[46] M. Ponz de Leon, G. Della Casa and P. Benatti, et al., Frequency and type of colorectal tumors in asymptomatic highrisk individuals in families with hereditary nonpolyposis colorectal cancer, Cancer Epidemiol Biomarkers Prev 7 (1998), 639-641.

[47] J.C. Clark, Y. Collan and T.J. Eide, et al., Prevalence of polyps in an autopsy series from areas with varying incidence of large-bowel cancer, Int J Cancer 36 (1985), 179-186.

[48] K.N. Syrigos, A. Charalampopoulos and J.L. Ho, et al., Colonoscopy in asymptomatic individuals with a family history of colorectal cancer, Ann Surg Oncol 9 (2002), 439-443.

[49] J.A. Bufill, Colorectal cancer: evidence for distinct genetic categories based on proximal or distal tumor location, Ann Intern Med 113 (1990), 779-788.

[50] B. Iacopetta, Are there two sides to colorectal cancer? Int J Cancer 101 (2002), 403-408.

[51] L.E. Johns and R.S. Houlston, A systematic review and metaanalysis of familial colorectal cancer risk, Am J Gastroenterol 96 (2001), 2992-3003.

[52] J. Breivik and G. Gaudernack, Genomic instability, DNA methylation, and natural selection in colorectal carcinogenesis, Semin Cancer Biol 9 (1999), 245-254.

[53] S. Salahshor, U. Kressner and L. Pahlman, et al., Colorectal cancer with and without microsatellite instability involves different genes, Genes Chromosomes Cancer 26 (1999), 247252.

[54] S.N. Thibodeau, G. Bren and D. Schaid, Microsatellite instability in cancer of the proximal colon, Science 260 (1993), 816-819.

[55] L.G. Johannsen, O. Momsen and N.O. Jacobsen, Polyps of the large intestine in Aarhus, Denmark, An autopsy study, Scand J Gastroenterol 24 (1989), 799-806.

[56] J.R. Jass, T.C. Smyrk and S.M. Stewart, et al., Pathology of hereditary non-polyposis colorectal cancer, Anticancer Res 14 (1994), 1631-1614.

[57] S.J. Lanspa, H.T. Lynch and T.C. Smyrk, et al., Colorectal adenomas in the Lynch syndromes. Results of a colonoscopy screening program, Gastroenterology 98 (1990), 1117-1122.

[58] F.E. Rijcken, T. van der Sluis and H. Hollema, et al., Hyperplastic polyps in hereditary nonpolyposis colorectal cancer, Am J Gastroenterol 98 (2003), 2306-2311.

[59] B. Hofstad, M. Vatn and S. Larsen, et al., Growth of colorectal polyps: recovery and evaluation of unresected polyps of less than $10 \mathrm{~mm}, 1$ year after detection, Scand J Gastroenterol 29 (1994), 640-645.

[60] J.D. Waye, Colon polyps: problems, promises, prospects, $A m$ J Gastroenterol 81 (1986), 101-103.

[61] K. Almendingen, B. Hofstad and M.H. Vatn, Does a family history of cancer increase the risk of occurrence, growth, and recurrence of colorectal adenomas? Gut 52 (2003), 747-751.

[62] S.P. Bensen, B.F. Cole and L.A. Mott, et al., Colorectal hyperplastic polyps and risk of recurrence of adenomas and hyperplastic polyps, Polyps Prevention Study, Lancet 354 (1999), 1873-1874.

[63] R.U. van Stolk, G.J. Beck and J.A. Baron, et al., Adenoma characteristics at first colonoscopy as predictors of adenoma recurrence and characteristics at follow-up. The Polyp Prevention Study Group, Gastroenterology 115 (1998), 13-18.
[64] O. Croizet, J. Moreau and Y. Arany, et al., Follow-up of patients with hyperplastic polyps of the large bowel, Gastrointest Endosc 46 (1997), 119-123.

[65] J.R. Jass, Serrated route to colorectal cancer: back street or super highway? J Pathol 193 (2001), 283-285.

[66] J.P. Terdiman, J.R. Gum Jr and P.G. Conrad, et al., Efficient detection of hereditary nonpolyposis colorectal cancer gene carriers by screening for tumor microsatellite instability before germline genetic testing, Gastroenterology 120 (2001), 21-30.

[67] A. Loukola, R. Salovaara and P. Kristo, et al., Microsatellite instability in adenomas as a marker for hereditary nonpolyposis colorectal cancer, Am J Pathol 156 (1999), 1849-1853.

[68] A. Loukola, A. de la Chapelle and L.A. Aaltonen, Strategies for screening for hereditary non-polyposis colorectal cancer, J Med Genet 36 (1999), 819-822.

[69] R. Salovaara, A. Loukola and P. Kristo, et al., Populationbased molecular detection of hereditary nonpolyposis colorectal cancer, J Clin Oncol 18 (2000), 2193-2200.

[70] T. Caldes, J. Godino and M. de la Hoya, et al., Prevalence of germline mutations of MLH1 and MSH2 in hereditary nonpolyposis colorectal cancer families from Spain, Int J Cancer 10 (2002), 774-779.

[71] A. Wagner, A. Barrows and J.T. Wijnen, et al., Molecular analysis of hereditary nonpolyposis colorectal cancer in the United States: high mutation detection rate among clinically selected families and characterization of an American founder genomic deletion of the MSH2 gene, Am J Hum Genet 72 (2003), 1088-1100.

[72] Y. Wang, W. Friedl and C. Lamberti, et al., Hereditary nonpolyposis colorectal cancer: frequent occurrence of large genomic deletions in MSH2 and MLH1 genes, Int J Cancer 20 (2003), 636-641.

[73] F. Charbonnier, S. Olschwang and Q. Wang, MSH2 in contrast to MLH1 and MSH6 is frequently inactivated by exonic and promoter rearrangements in hereditary nonpolyposis colorectal cancer, Cancer Res 62 (2002), 848-853.

[74] C.F. Taylor, R.S. Charlton and J. Burn, et al., Genomic deletions in MSH2 or MLH1 are a frequent cause of hereditary non-polyposis colorectal cancer: identification of novel and recurrent deletions by MLPA, Hum Mutat 22 (2003), 428-433.

[75] F. Charbonnier, G. Raux and Q. Wang, et al., Detection of exon deletions and duplications of the mismatch repair genes in hereditary nonpolyposis colorectal cancer families using multiplex polymerase chain reaction of short fluorescent fragments, Cancer Res 60 (2000), 2760-2763.

[76] A.L. Borresen, R.A. Lothe and G.I. Meling, et al., Somatic mutations in the hMSH2 gene in microsatellite unstable colorectal carcinomas, Hum Mol Genet 11 (1995), 2065-2072.

[77] K. Shitoh, F. Konishi and M. Miyaki, et al., Pathogenesis of non-familial colorectal carcinomas with high microsatellite instability, J Clin Pathol 53 (2000), 841-845.

[78] S. Salahshor, K. Koelble, C. Rubio and A. Lindblom, Microsatellite Instability and hMLH1 and hMSH2 expression analysis in familial and sporadic colorectal cancer, Lab Invest 81 (2001), 535-541.

[79] J.M. Cunningham, E.R. Christensen and D.J. Tester, et al., Hypermethylation of the hMLH1 promoter in colon cancer with microsatellite instability, Cancer Res 58 (1998), 34553460 .

[80] S.A. Kuismanen, M.T. Holmberg, R. Salovaara, A. de la Chapelle and P. Peltomaki, Genetic and epigenetic modification of MLH1 accounts for a major share of microsatelliteunstable colorectal cancers, Am J Pathol 156 (2000), 17731779 . 
[81] M. Menigatti, C. Di Gregorio and F. Borghi, et al., Methylation pattern of different regions of the MLH1 promoter and silencing of gene expression in hereditary and sporadic colorectal cancer, Genes Chromosomes Cancer 31 (2001), 357-361.

[82] J.M. Cunningham, C.Y. Kim and E.R. Christensen, et al., The frequency of hereditary defective mismatch repair in a prospective series of unselected colorectal carcinomas, Am J Hum Genet 69 (2001), 780-790.

[83] R. Ward, A. Meagher and I. Tomlinson, et al., Microsatellite instability and the clinicopathological features of sporadic colorectal cancer, Gut 48 (2001), 821-829.

[84] J. Plaschke, S. Kruger and S. Pistorius, et al., Involvement of hMSH6 in the development of hereditary and sporadic colorectal cancer revealed by immunostaining is based on germline mutations, but rarely on somatic inactivation, Int J Cancer 97 (2002), 643-648.

[85] N.M. Lindor, L.J. Burgart and O. Leontovich, et al., Immunohistochemistry versus microsatellite instability testing in phenotyping colorectal tumors, J Clin Oncol 20 (2002), 10431048.

[86] T. Liu, P. Tannergard and P. Hackman, et al., Missense mutations in hMLH1 associated with colorectal cancer, Hum Genet
105 (1999), 437-441.

[87] S. Wahlberg, T. Liu and P. Lindblom, et al., Various mutation screening techniques in the DNA mismatch repair genes hMSH2 and hMLH1, Genet Test 3 (1999), 259-264.

[88] R.W. Burt, Colon cancer screening, Gastroenterology 119 (2000), 837-853.

[89] J.G. Guillem, A.J. Smith, J.P. Calle and L. Ruo, Gastrointestinal polyposis syndromes, Curr Probl Surg 36 (1999), 217323.

[90] G. Marra and C.R. Boland, Hereditary nonpolyposis colorectal cancer: the syndrome, the genes, and historical perspectives, J Natl Cancer Inst 87 (1995), 1114-1125.

[91] H.T. Lynch and A. de la Chapelle, Genetic susceptibility to non-polyposis colorectal cancer, J Med Genet 36 (1999), 801818.

[92] W. Burke, G. Petersen and P. Lynch, et al., Recommendations for follow-up care of individuals with an inherited predisposition to cancer. I. Hereditary nonpolyposis colon cancer. Cancer Genetics Studies Consortium, JAMA 277 (1997), 915-919.

[93] S.V. Hodgson, D.T. Bishop, M.G. Dunlop, D.G. Evans and J.M. Northover, Suggested screening guidelines for familial colorectal cancer, J Med Screen 2 (1995), 45-51. 


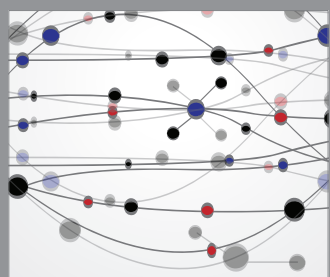

The Scientific World Journal
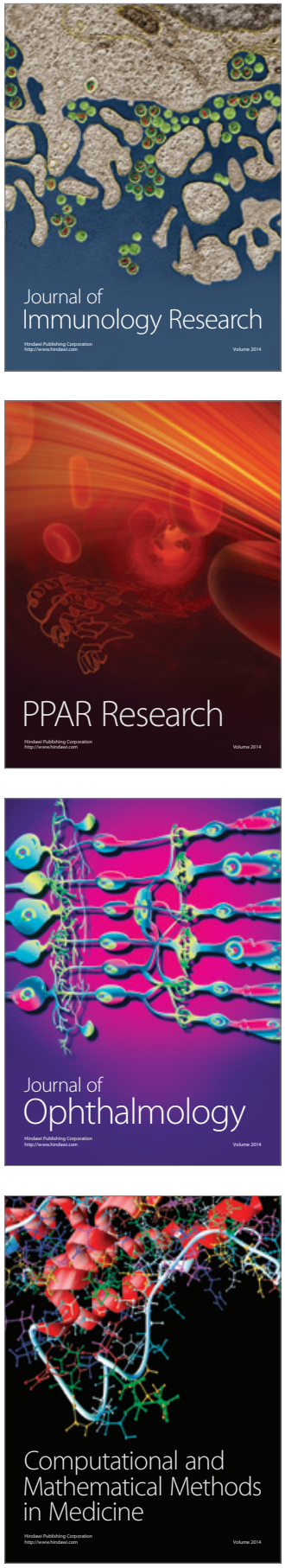

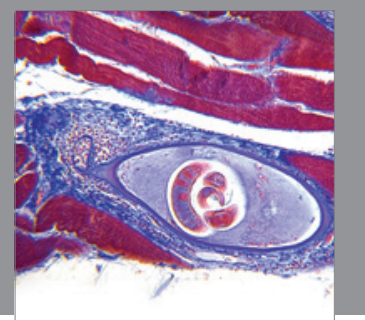

Gastroenterology

Research and Practice
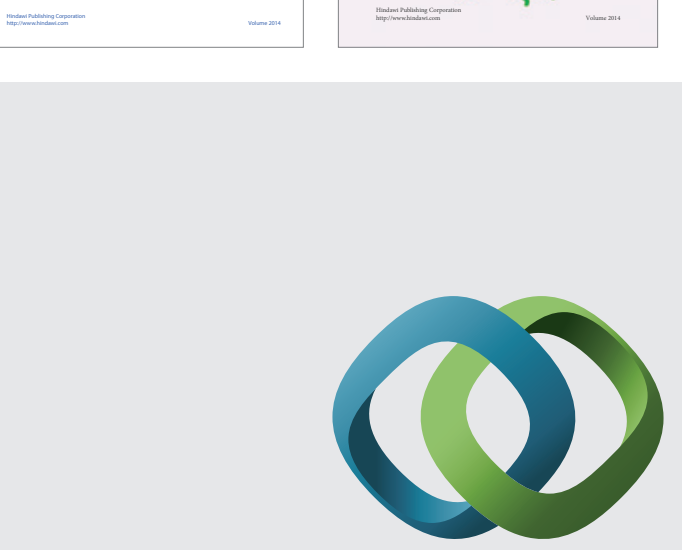

\section{Hindawi}

Submit your manuscripts at

http://www.hindawi.com
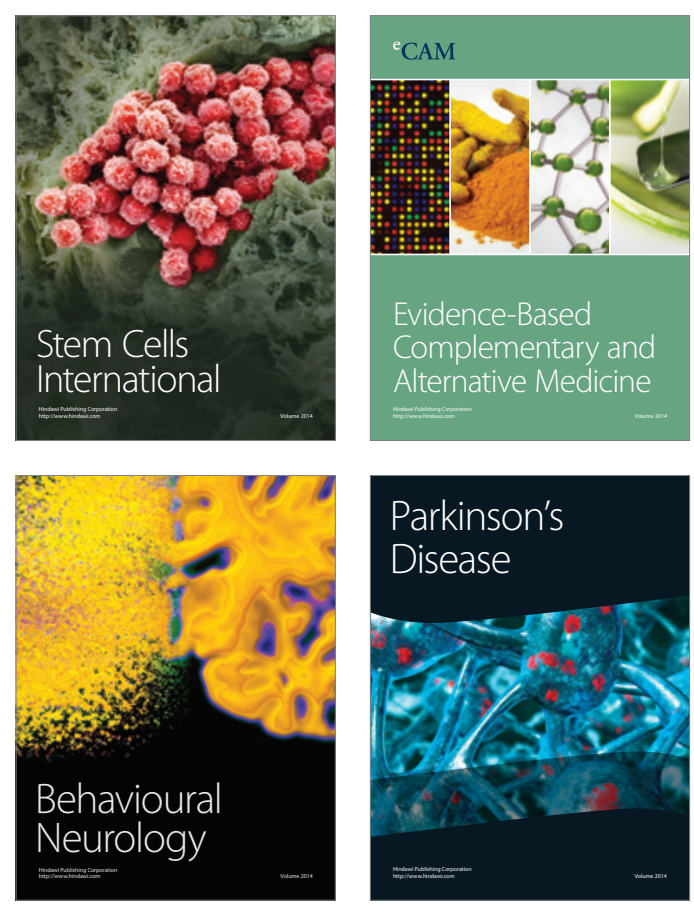

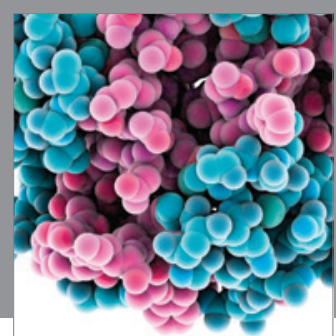

Journal of
Diabetes Research

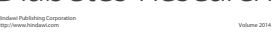

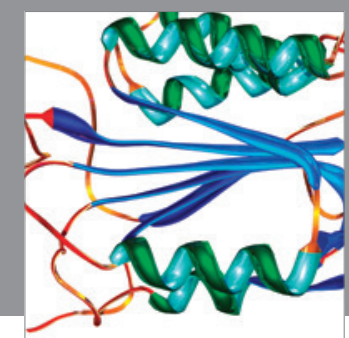

Disease Markers
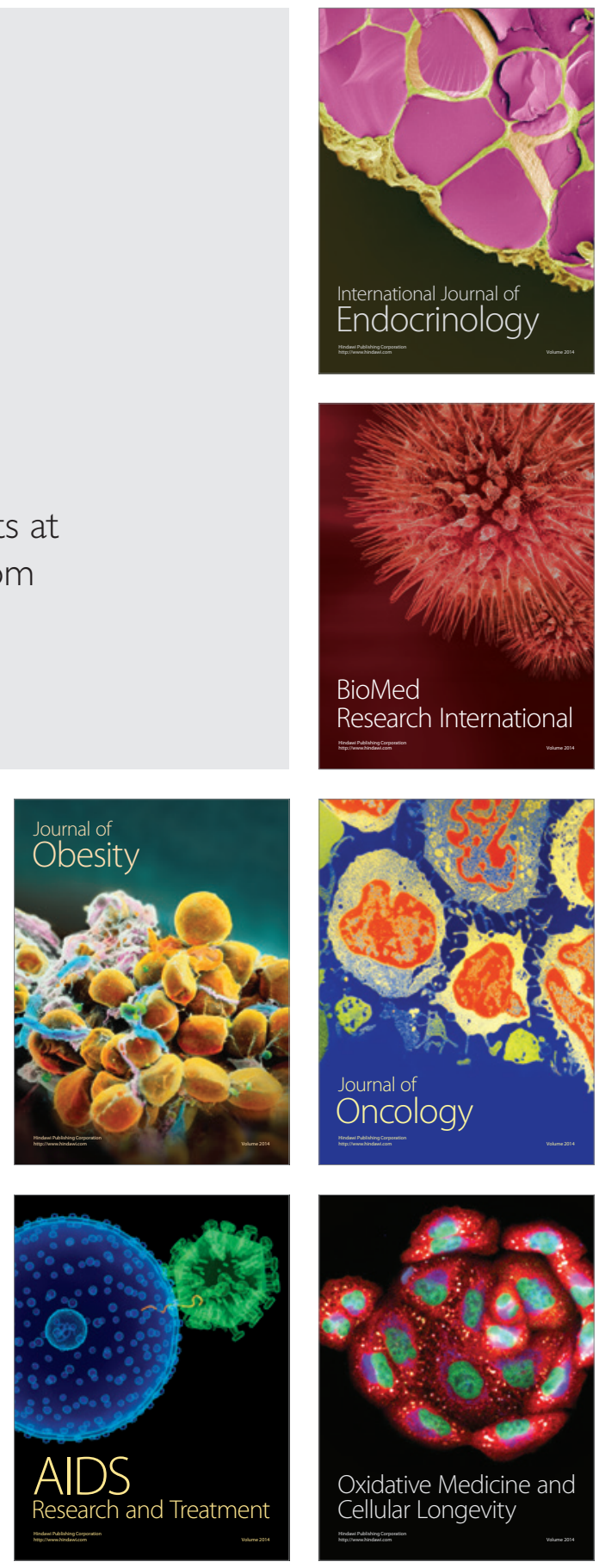